a debilitating febrile illness lasting a year or more. Treatment remains unsatisfactory, so that every attempt should be made to prevent infection. This must depend on a reduction of contacts between dog faeces and people, especially children. Those who keep dogs and children in the same house should at least ensure that the dogs are regularly-and frequentlywormed.

\footnotetext{
1 Wilder, H C, Transactions of the American Academy of Ophthalmology, 1950, 55, (Nov-Dec) 99.

${ }^{2}$ Mercer, R, et al, American fournal of Diseases of Children, 1950, 80, 46.

${ }^{3}$ Beaver, P C, et al, Pediatrics, 1952, 9, 7.

${ }^{4}$ Beaver, P C, Experimental Parasitology, 1956, 5, 587.

5 Stone, W, and Smith, F W, Experimental Parasitology, 1973, 34, 306.

${ }^{6}$ Zinkham, W H, American fournal of Diseases of Children, 1978, 132, 627.
}

\section{Bundle branch block}

Tiny deviations from the normal pattern on a strip of paper may be fraught with importance: an abnormal electrocardiogram (ECG) alone may ruin a man's career. ${ }^{12}$ The telltale deformities of the QRS complex called bundle branch block are the only evidence we have that depolarisation of the ventricles is pursuing an abnormal course and that one day the electrical union between atria and ventricles may be severed. A prolonged PR interval may be observed too, but in most cases of bundle branch block this is in the normal range of less than 0.22 seconds. Bundle branch block is rare: in a population of over 28000 attending a screening centre in Belgium the incidence of left bundle branch block was $0.6 \%$ in men and $0.88 \%$ in women. Right bundle branch block was found in $1.31 \%$ of men and $0.64 \%$ of women. ${ }^{3}$ Among 42000 patients having ECGs in hospital $0.77 \%$ had bundle branch block, ${ }^{4}$ though the incidence was many times less in large surveys of United States Air Force personnel. ${ }^{5-7}$

Our understanding of heart block and bundle branch block was greatly advanced about ten years ago by the development of His bundle recording. ${ }^{8}$ This exquisite example of applied electrophysiology has resulted in an explosion of research interest. When the electrode catheter is carefully positioned across the tricuspid valve and the electrical potentials are suitably amplified three deflections are seen: A, which corresponds to the $P$ wave of the surface electrocardiogram and coincides with depolarisation of the lower portion of the right atrium; $\mathrm{H}$, a small deflection, caused by depolarisation of the bundle of His; and V, which reflects depolarisation of the ventricles and corresponds to the QRS complex of the surface ECG. Measurement of the intervals A-H and $\mathrm{H}-\mathrm{V}$ and of the duration of the His deflection itself provides information on the level of delayed or blocked conduction, which may be supra-, intra- or infra-His. The first type usually represents delayed conduction in the atrioventricular node, and the third delayed conduction in the bundle branches or Purkinje network.

At about the time that His bundle recording became fashionable Rosenbaum ${ }^{910}$ popularised the concept of ventricular activation by three channels or fascicles: the right bundle branch, and the anterior and posterior divisions of the left bundle branch. The ECG interpretation of right and left bundle branch block stood as before, but the new concepts of left anterior and left posterior hemiblock were introduced and approved, ${ }^{11}$ and with them the terms single, bifascicular, and trifascicular block. The ECG manifestation of left anterior hemiblock is left axis deviation, and of right posterior hemiblock right axis deviation, though the definition of the precise degree of axis shift is arbitrary. Histologists ${ }^{12} 13$ point out that the left bundle seldom if ever shows two recognisable divisions but is a fan-shaped structure; the electrophysiologists agree that this may be so but that the concept is functionally useful; and clinicians all over the world have adopted the terminology.

To the practising cardiologist the potential importance of His bundle recording lies in its ability to predict-if it canwhich of his patients with fascicular block, though free from symptoms at present, are most at risk from heart block and Stokes-Adams attacks in the future-and might therefore stand to benefit from a pacemaker. For example, if two fascicles are blocked prolongation of the $\mathrm{H}-\mathrm{V}$ interval in the remaining conducting channel might imply a special risk from syncope or sudden death. Such notions have prompted many His bundle studies, ${ }^{14-18}$ but unfortunately their conclusions have not been uniform. McAnulty and colleagues ${ }^{19}$ have now reported a prospective study, with an average follow-up of 25 months, of 257 patients with high risk bundle branch block (bifascicular or trifascicular) all of whom had His bundle studies and none of whom had a documented bradyarrhythmia or implanted pacemaker at the time of evaluation. These patients formed a selected group culled from a survey of 125000 ECGs, of which 1211 showed bifascicular or trifascicular block (an incidence of $0.96 \%$ ). Though 50 patients died in the follow-up period, death was sudden in only 27 and in 17 of these was not due to bradyarrthythmia. Those with a prolonged PR or HV interval, and even those with a history of syncope, failed to emerge as a group especially prone to sudden death. These results emphasise that the poor prognosis usually attributed to bundle branch block in statements of the overall mortality rate $^{1920}$ is not necessarily due to failure of atrioventricular conduction but frequently to other consequences of cardiac disease.

We should therefore avoid hasty decisions in the management of asymptomatic bundle branch block. If the subject's livelihood is at stake investigation by His bundle recording or coronary angiography may be justified: aircrew in the United States Air Force have even been permitted to fly after such evaluation. ${ }^{7}$ As to general anaesthesia for surgery, the risk of provoking complications from heart block appears to be small, ${ }^{21}$ and protection by a temporary pacemaker is seldom indicated. Permanent pacing is still best reserved for patients in whom atrioventricular block has been found together with a history of syncope or other symptoms related to bradycardia; prophylactic pacing in asymptomatic patients with bifascicular or trifascicular block appears unjustified-at least until further conduction studies have identified a group particularly at risk. ${ }^{19}$

\footnotetext{
${ }^{1}$ Medical Aspects of Fitness to Drive, 3rd ed, Medical Commission on Accident Prevention. London, 1976.

2 Working Party of the Cardiology Committee, Royal College of Physicians of London, British Heart fournal, 1978, 40, 335.

${ }^{3}$ Kulbertus, H E, et al, American fournal of Cardiology, 1978, 41, 385.

4 McAnulty, J H, et al, Archives of Internal Medicine, 1978, 138, 30.

${ }^{5} \mathrm{Lamb}, \mathrm{L}$ E, Kable, K D, and Averill, K H, American fournal of Cardiology, 1960, 6, 130.

${ }^{6}$ Johnson, R L, Averill, K H, and Lamb, L E, American fournal of Cardiology, 1960, 6, 143.

${ }^{7}$ Rotman, M, and Triebwasser, J H, Circulation, 1975, 51, 477.

${ }^{8}$ Scherlag, B J, et al, Circulation, 1969, 39, 13.

${ }^{9}$ Rosenbaum, M B, et al, American Heart fournal, 1969, 78, 450.

10 Rosenbaum, M B, Modern Concepts of Cardiovascular Disease, 1970, 39, 141.

11 Trevino, A J, and Beller, B M, American fournal of Medicine, 1971, 51, $362,374$.

12 Massing, G K, and James, T N, Circulation, 1976, 53, 609.
} 
13 Anderson, R H, and Becker, A E, British Heart fournal, 1978, 40, suppl, p 2.

14 Levites, R, and Haft, J I, American fournal of Cardiology, 1974, 34, 259. 15 Dhingra, R C, et al, American fournal of Cardiology, 1975, 36, 867.

${ }_{16}$ Dhingra, R C, et al, Circulation, 1976, 53, 600.

17 Vera, Z, et al, Circulation, 1976, 53, 46.

18 Scheinman, M M, et al, Circulation, 1977, 56, 240

19 McAnulty, J H, et al, New England Fournal of Medicine, 1978, 299, 209.

20 Graybiel, A, and Sprague, H B, American fournal of Medical Sciences, 1933, 185, 395.

${ }^{21}$ Pastore, J O, et al, Circulation, 1978, 57, 677.

\section{Vitamin C, disease, and surgical trauma}

Vitamin C is concerned with the integrity of connective tissue constituents, particularly collagen and intracellular cement substance, but its precise mode of action is still not clear. ${ }^{1}$ The Medical Research Council study in Sheffield during the second world war showed that a daily dietary intake of $10 \mathrm{mg}$ ascorbic acid could prevent or cure overt signs of scurvy. ${ }^{2}$ In Britain today scurvy is seen only rarely-mainly in mentally handicapped children and elderly people. Experimentally, it has developed in human volunteers fed on a diet containing no vitamin C, the normal body pool of $1500 \mathrm{mg}$ being depleted at the rate of about $3 \%$ daily. $^{3}$ Clinical manifestations of scurvy appear after 84-97 days, when the body pool is less than $300 \mathrm{mg}$ : they include fatigue, petechial haemorrhages, follicular hyperkeratosis, aching limbs, swollen and bleeding gums, and effusions into the joints. But even before physical signs appeared in the volunteers psychometric tests ${ }^{4}$ showed personality changes, notably hypochondriasis and depression, followed by a decline in psychomotor performance that was associated with reduced arousal and motivation. A severe depressive state is reported as a striking clinical feature in chronic scurvy, but this clears after a few days of vitamin C treatment. ${ }^{5}$

Anaemia is common in vitamin C deficiency, which may cause continued gastrointestinal haemorrhage once this has been precipitated by gastric irritants such as aspirin. ${ }^{6}$ The anaemia is usually normocytic or macrocytic with normoblastic or macronormoblastic erythropoiesis, but true megaloblastic anaemia also occurs. ${ }^{78}$ The anaemia is usually due to several factors: haemolysis, bleeding, dietary deficiency of iron, and derangement of red cell metabolism have been incriminated. ${ }^{9}$ Megaloblastic change possibly results from either an associated dietary folate deficiency or the impairment of folate metabolism in scurvy. ${ }^{10}$ In the absence of vitamin $C$ tetrahydrofolates are oxidised to 10-formyl folic acid; and an important role of vitamin $\mathrm{C}$ in metabolism is probably maintaining an available metabolic pool of folate.

Increasing the vitamin $\mathrm{C}$ content of the diet fed to guinea pigs increases the wound strength in healing skin. ${ }^{11}$ Though in man wound healing can proceed satisfactorily with low intakes of vitamin C-less than $10 \mathrm{mg}$ daily-more may be needed in special circumstances. Thus biopsy specimens taken before and after treatment from paraplegic patients with pressure sores showed more intense staining for collagen when they had taken $1 \mathrm{~g}$ of ascorbic acid for three days, an effect not produced by placebo. ${ }^{12}$ Though none of the patients showed evidence of vitamin $\mathrm{C}$ deficiency, the increased intake could have helped clinically. Crandon and his colleagues ${ }^{13}$ suggested that surgical operations result in increased requirements for vitamin $C$, and that deficiency is a common and important factor in wound complications after operation. Their findings have been questioned, however, owing to the difficulties of interpreting the alterations in the concentrations of ascorbic acid in the buffy layer or plasma that accompany postoperative metabolic and haematological changes. Recently Irvin and his co-workers ${ }^{14}$ in Sheffield have reassessed ascorbic acid requirements after operation in patients grouped according to the severity of the surgical trauma. The leucocyte ascorbic acid (LAA) concentrations were significantly reduced after operation. The reductions were unrelated to the severity of surgical trauma or to the volume of blood transfused at operation, but there was a significant inverse correlation between LAA concentrations and white blood counts. The authors conclude that postoperative leucocytosis due to surgical trauma and the release by the bone marrow of leucocytes with a low ascorbic acid content may partly account for the postoperative changes in LAA measurements. Nevertheless, surgical operations were evidently followed by an authentic increase in ascorbic acid requirements since circulatory LAA concentrations fell by $42 \%$ on the third day. The results of the Sheffield study support the argument for ascorbic acid supplements in patients having surgery even though their benefits have not been assessed.

In a series of aged hospital patients the death rate was $47 \%$ in the four weeks after admission for those whose initial LAA concentration was under $0.68 \mu \mathrm{mol}(12 \mu \mathrm{g}) / 10^{8}$ leucocytes but only $10 \%$ when it was over $1.42 \mu \mathrm{mol}(25 \mu \mathrm{g}) / 10^{8}$ leucocytes $(\mathrm{P}<0.01) .{ }^{15}$ The mortality rate turned out, however, to be related not to LAA concentration directly but to the severity of the illness, which in turn influences the tissue stores of vitamin C. ${ }^{16}$ In the follow-up study administration of vitamin $\mathrm{C}$ failed to produce an increase in LAA concentrations in many of the patients nor did it influence the death rate. Thus the disturbances of metabolism that occur in many diseases-as well as several drugs, including tetracycline ${ }^{17}-$ are likely to depress the LAA concentration. But how far do ascorbic acid concentrations in the tissues influence the course of diseases (and the efficacy of treatment) as well as the rate of wound healing? This is a question we cannot answer until we have more sensitive tests to detect impaired collagen function. Meanwhile we need further evaluations of the effects of vitamin $\mathrm{C}$ supplements on wound healing in patients undergoing surgery.

${ }^{1}$ Department of Health and Social Security, Recommended Intakes of Nutrients for the United Kingdom. Reports on Public Health and Medical Subjects No 20. London, HMSO, 1969.

2 Bartley, W, Krebs, H A, and O'Brien, J R P, Vitamin C Requirements of Human Adults. MRC Special Report Series 280, London, HMSO, 1953. ${ }^{3}$ Hodges, R E, et al, American fournal of Clinical Nutrition, 1971, 24, 432. 4 Kinsman, R A, and Hood, J, American fournal of Clinical Nutrition, 1971, 24, 455.

5 Walker, A, British fournal of Dermatology, 1968, 80, 625.

- Russell, R I, et al, Lancet, 1968, 2, 603.

7 Hyams, D E, and Ross, E J, British fournal of Clinical Practice, 1963, 17, 332.

${ }^{8}$ Goldberg, A, Ouarterly fournal of Medicine, 1963, 32, 51.

9 Cox, E V, Vitamins and Hormones, 1968, 26, 635.

10 Stokes, P L, et al, American fournal of Clinical Nutrition, 1975, 28, 126.

11 Hughes, R E, Hurley, R J, and Jones, P R, British Fournal of Nutrition, 1971, 26, 433.

12 Hunter, T, and Rajan, K T, Paraplegia, 1971, 8, 211.

13 Crandon, J H, et al, Annals of the New York Academy of Sciences, 1961, $92,246$.

14 Irvin, T T, Chattopadhyay, D K, and Smythe, A, Surgery, Gynecology and Obstetrics, 1978, 147, 49.

15 Wilson, T S, et al, Gerontologia Clinica, 1972, 14, 17.

16 Wilson, T S, et al, Age and Ageing, 1973, 2, 163.

17 Windsor, A C M, et al, British Medical fournal, 1972, 1, 214. 